\title{
The Role of Farmers' Social Networks in Adopting Climate Smart Ag- riculture: Case of Horticultural Farmers in Nyeri County, Kenya
}

\author{
Joram Ngugi Kamau $^{1^{*}}$ Ibrahim Nyariki Kiprop $^{2}$ Geoffrey Kosgei Kipruto $^{2}$
}

1. Department of Agricultural Economics and Agribusiness Management, Egerton University, Kenya

2. Department of Agribusiness Management and Agricultural Education, Chuka University, Kenya

\begin{tabular}{l}
\hline ARTICLE INFO \\
\hline Article history \\
Received: 1 December 2020 \\
Revised: 7 December 2020 \\
Accepted: 8 December 2020 \\
Published Online: 30 December 2020 \\
\hline
\end{tabular}

Keywords:

Farmers' social networks

Conservation agriculture

Centrality measures

\begin{abstract}
This paper aimed at depicting how farmers use their informal networks to share information on climate smart agriculture especially on conservation agriculture. The study used social network analysis (SNA) in UCINET to depict the pattern of information sharing on conservation agriculture among individual farmers and farmer groups. The study identified the structural importance of various actors in the farmers' social networks. Power and centrality measures of various farmers were identified. Values for ego betweenness, coordinator and gatekeeper brokerage roles were normalized so that differences in network sizes were accounted for. The study identified several farmers who were identified to be critical in information sharing among horticultural farmers in Nyeri County. Farmers' social networks were found to play a pivotal role in the dissemination of information with key farmers identified as central actors in the network. Social network theory examines social structure from the perspective that relationships between two parties or more are partly influenced by the external ties possessed by each other with the degree of influence varying among the actors. This research demonstrates the need for agricultural research institutions to identify and liaise with actors with high degree of centrality in the jurisdiction of information and resource dissemination to guarantee maximum adoption of new technologies by the target groups.
\end{abstract}

revenue from exports ${ }^{[3]}$.

The Food and Agriculture Organization (FAO) of the United Nations in 2010 defined Climate Smart Agriculture (CSA) as agriculture that would have three components; Sustainably increasing agricultural productivity and incomes; Adapting and building resilience to climate change and Reducing and/or recovering greenhouse gases emissions where applicable ${ }^{[4]}$. CSA is an approach aimed at developing the technical, policy and investment conditions to achieve sustainable agricultural development for food security under climate change ${ }^{[5]}$.

A report by Kenya Climate Smart Agriculture Imple-

*Corresponding Author:

Joram Ngugi Kamau,

Department of Agricultural Economics and Agribusiness Management, Egerton University, Kenya;

Email:ngugij88@gmail.com 
mentation Framework (KCSAIF) 2018-2027 indicates that Kenya has experienced rising temperatures over the last 50 years coupled with intense and extreme weather events like droughts and floods. According to the report, future climatic predictions for Kenya indicate possible temperature increase of $1^{\circ} \mathrm{C}$ by 2020 and $2.3^{\circ} \mathrm{C}$ by $2050^{[6]}$.

According to Kabubo and Kabara, agricultural production in Kenya has been on the decline from 2015 to 2018 due to erratic weather conditions during the period. With declining production juxtaposed by an exponentially growing population, food security and household welfare of farmers are adversely affected. According to the Ministry of Agriculture, Livestock and Fisheries (MoALF), about $98 \%$ of Kenya's agricultural activities are rain-fed and therefore highly susceptible to climate change and climate variability ${ }^{[7]}$.

Climate Smart Agriculture is a recent occurrence in Kenya that was launched in 2017 by the MoALF with an aim of building an agricultural system that will sustainably increase productivity, adapt and build resilience to the likely effects of climate change and reduce/or remove greenhouse gas emissions without compromising productivity ${ }^{[7]}$. This will be achieved through; access to and use of adaptive technologies, increase area under efficient irrigation, value addition and products development, competitiveness and markets access for climate smart products and coordinated food storage and distribution ${ }^{[7]}$.

With the effects of global warming evident in Kenya, agricultural sector has become sensitive and highly vulnerable to climate change and variability in terms of prolonged dry spells, droughts, floods and other extreme events. Due to the high dependency on rain fed agriculture amongst farmers in Kenya, Recha found that agricultural productivity has decreased by $1 \%$ in the last decade due to climate related adversities. According to the study, smallholder farmers in Kenya, oblivious of their actions, are gradually adopting sustainable agricultural practices as a reflex action towards the impacts climate change ${ }^{[8]}$.

This study conceptualized climate smart agriculture as an activity or process that horticultural farmers in Kieni exercise with a view of ensuring sustainable agriculture. With the adoption of climate smart and ecologically sustainable production methods along the agricultural value chain, agricultural productivity, food security and household income will be sparked across the country. These methods include among others; minimum tillage, crop rotation, crop diversification, water harvesting and irrigation.

\section{Materials and Methods}

The sample unit for this study consisted of smallholder horticultural farmers drawn from Kieni administrative constituency in Nyeri County. First, Nyeri County was purposively selected because of the large number of small-scale horticultural farmers. Within the County, Kieni Sub-County was also purposively selected because this is where intensive horticultural farming is done. Two sub-locations were also purposively selected from this sub-county. Households were randomly selected within the sub-locations to yield a sample size of 100 farmers who acted as the egos where alters' networks were generated. These sub-locations were selected based on their similar rural classification, close proximity to each other and their similarities in terms of livelihood activities, which predominantly are horticultural farming areas.

Structured questionnaires were prepared to collect quantitative data for the study. Primary data sources for the study were the sampled farm households, both male and female heads. The developed questionnaires were pretested to evaluate for consistency, clarity and to avoid duplication. Network interviews were conducted as part of the household survey during the fieldwork. A person-based data collection strategy was employed within the household survey questionnaire and from this; a set of indicators, each referring to different aspects of social networks, were constructed.

A name generator approach was employed when the interviewed household heads (egos) were asked to name people from whom they get information from. The first step was whether from extension officers, radio, television or from fellow farmers. Those who indicated to get information from fellow farmers (alters) were qualified for network mapping and therefore a follow-up question was to list alters' names and attributes.

Alters' names were recorded in response matrices which were later coded during the analysis. Further questions were posed concerning attributes of the network partner (sex, age and geographical locations), the nature of the relationship between network partner and household heads and multiple role relationships. This data formed the "interaction" network of the household head.

\section{Results}

From the 100 sampled farmers, each farmer (henceforth referred to as ego) was probed to identify the contacts they rely on to source information (henceforth referred to as alters). Each ego was to identify utmost three contacts from which they get information on climate smart agriculture. The egos were coded numerically from 1 to 100 while each ego's alters were coded as the numerical number of the ego with alphabets $\mathrm{A}, \mathrm{B}$ and $\mathrm{C}$ representing the first to the third alter chronologically. The multiplier effect was a 
net of 293 actors.

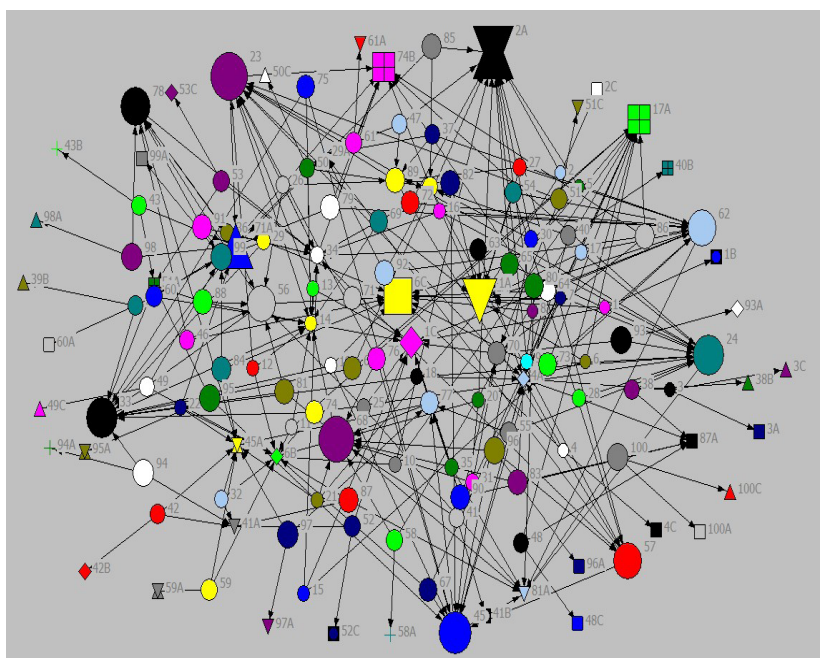

Figure 1. Farmers Sociograph

Figure 1 illustrates the network structure revealed by farmers in Nyeri county. The size of the node is identical to its in-degree centrality. The larger the node, the higher the level of its centrality measure and vice versa. Nodes 2A, 17A, 23, 24, 33 and 45 recorded the largest degree of centrality. The implication is that the sampled farmers in Kieni Sub County identified the listed farmers as the most valuable information contacts on climate smart agriculture. These were the farmers that practiced conservation agriculture in their horticultural management practices.

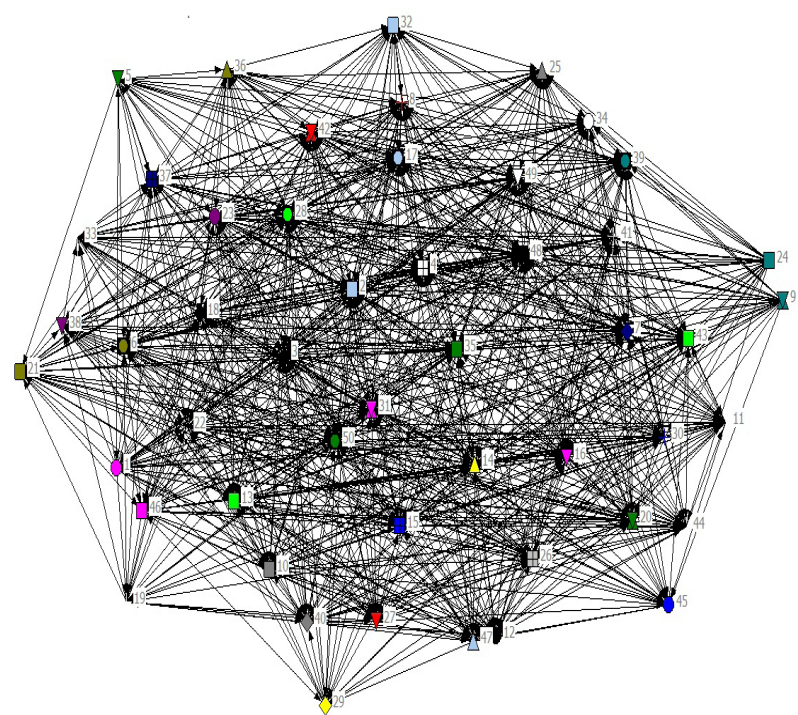

Figure 2. Ego's Network

Figure 2 represents the structure of the egos network where egos happened to rely on other egos to get information on climate smart agriculture. To help describe the network composition and affiliations, a follow-up on the sampled egos (who were alters as well) was probed to identify their relationship. This is captured by the network affiliations in Figure 3.

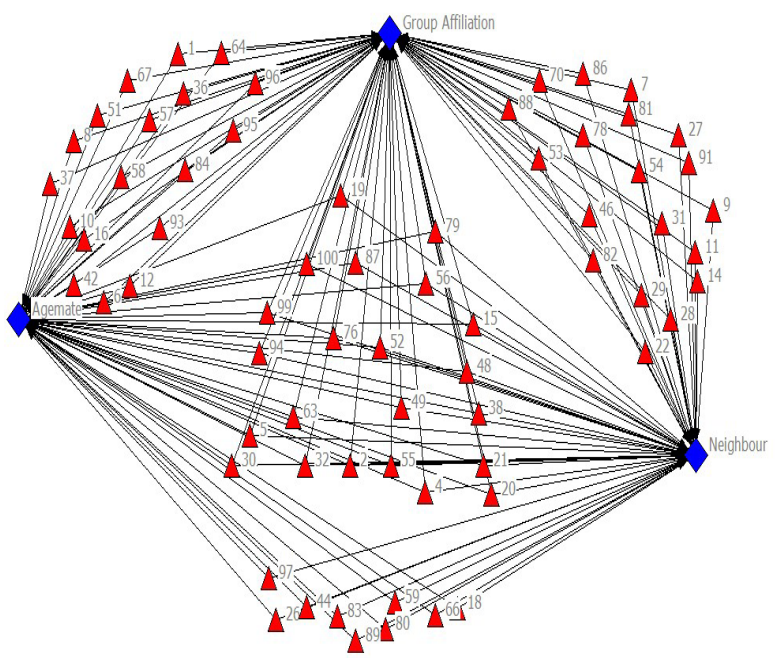

Figure 3. Network Affiliations

The heterogeneous nature of the farmer's network in Kieni as indicated in Figure 3 is an important phenomenon in network theories. First, similarity breeds connections and that individuals with a similarity in character will act as a pull factor. Secondly, the mix element in the net heterogeneity ensures that a diverse distribution and dissemination of resources and information is guaranteed. With such a mix of farmers, diversity in approaching conservation agriculture is guaranteed where input variation across various affiliations deter information and resource "inbreeding".

\section{Discussions and Conclusion}

From Figure 1, the economic importance of the farmers is that they are valuable media in information and resource dissemination. If these actors can be tapped, empowered and be resource endowed, they can be used by the government to transmit agricultural information to farmers in an efficient and economic manner.

Farmers 2A, 33 and 6C from Figure 1 recorded the highest level of betweeness centrality. The isolate nodes were disregarded as they don't meet the network threshold. The assumption was, for a farmer to be in a network matrix, he/she must have at least one in-degree and out-degree centrality. Betweeness centrality is a critical concept in a network map. Farmers 2A, 33 and 6C are very vital in connecting otherwise the unconnected others. They act as gatekeepers and their brokerage role in the flow of resources and information is very vital. In their absence, the network would be disconnected and are therefore information bridges.

Figure 3 describes the network affiliations in terms 
of neighbourhood, group membership and age mates. These three aspects were identified to be critical in describing the network homophily. Communities' informal networks in the country remain as untapped avenues that can be used to supplement the extension services by the government. As indicated by the study, farmers rely on fellow farmers to get new information and resources as opposed to the conventional extension service providers.

Social networks especially in agricultural management practices remain widely unexploited and therefore remain as a viable avenue for information dissemination across the country. It's imperative that agricultural research institutions identifies and liaise with actors with high degree of centrality in the jurisdiction of information and resource dissemination. Furthermore, the demonstration projects on sustainable agriculture in the country should be integrated based on the structural and network centralities of the target communities to ensure maximum adoption of new technologies. With increased risk and uncertainty in agrarian economy due to effects of global warming, climate smart agriculture is inevitable.

\section{Acknowledgments}

The study wishes to acknowledge all the horticultural farmers interviewed especially in Kiawara and Chaka administrative wards of Nyeri County. Special thanks go to the enumerators involved in data collection.

\section{Declaration of Interest Statement}

There is no any conflict of interest whatsoever among the authors or any other party.

\section{Funding Source}

There was no external source of funding other than the authors' contributions.

\section{References}

[1] Davis, C. L., Vincent, K. Climate risk and vulnerability: A handbook for Southern Africa, 2017.

[2] Conceição, P., Levine, S., Lipton, M., Warren-Rodríguez, A. Toward a food secure future: Ensuring food security for sustainable human development in Sub-Saharan Africa. Food Policy, 2016, 60: 1-9.

[3] Kanyua, M. J., Waluse, G. K. I. S. K., Wairimu, W. R. Factors influencing profitability of diversified cash crop farming among smallholder tea farmers in Gatanga District, Kenya. Journal of Economics and Sustainable Development, 2015.

ISSN: 2222-1700

[4] Jost, C., Kyazze, F., Naab, J., Neelormi, S., Kinyangi, J., Zougmore, R., Nelson, S. Understanding gender dimensions of agriculture and climate change in smallholder farming communities. Climate and Development, 2016, 8(2): 133-144.

[5] Lipper, L., Thornton, P., Campbell, B. M., Baedeker, T., Braimoh, A., Bwalya, M., Hottle, R. Climate-smart agriculture for food security. Nature climate change, 2014, 4(12): 1068-1072.

[6] Kabubo-Mariara J., Kabara, M. Climate change and food security in Kenya.In Agricultural Adaptation to Climate Change in Africa, Routledge, 2018: 55-80.

[7] Republic of Kenya. MOALF: Economic Review of Agriculture [ERA] 2018.Central Planning and Project Monitoring Unit, MOALF, Nairobi, Kenya, 2018. Available at:

http://www.kilimo.go.ke/wp-content/uploads/2018/10/Economic-Review-of-Agriculture_2018-2.pdf [Accessed on 2nd February, 2020]

[8] Recha, J. W., Mati, B. M., Nyasimi, M., Kimeli, P. K., Kinyangi, J. M., Radeny, M. Changing rainfall patterns and farmers' adaptation through soil water management practices in semi-arid eastern Kenya. Arid Land Research and Management, 2016, 30(3): 229-238. 